\title{
Sources and fates of heavy metals in complex, urban aquatic systems: modelling study based on Stockholm, Sweden
}

\author{
M. E. Malmström, V. Rolli, Q. Cui \& N. Brandt \\ Industrial Ecology, Royal Institute of Technology (KTH), \\ Stockholm, Sweden
}

\begin{abstract}
Despite management of point sources, heavy metals today remain at an elevated level in the urban environment, with diffuse sources dominating the emissions. In order to manage these pollutants, it is necessary to understand the coupling between the urban sources of heavy metals and their monitored, environmental levels, for example in aquatic sediments. In this work, we suggest a simple approach to quantitatively model $\mathrm{Cu}$ from its urban sources through a complex aquatic system. We apply the proposed model to Stockholm, situated between Lake Mälaren and the archipelago of the Baltic sea, and discuss data availability along with conceptual difficulties. Using literature data, we show that $\mathrm{Cu}$ occurs at elevated levels in the aquatic sediment close to the centre of Stockholm, Sweden.
\end{abstract}

Keywords: source, fate, copper, modelling, urban, aquatic system.

\section{Introduction}

Despite management of point sources, heavy metals today remain at an elevated level in the urban environment, with diffuse sources becoming dominant and with extensive internal loading within the aquatic systems. In order to manage these pollutants, increased knowledge of the sources and fates of urban metals is required. Particularly, there is a need for understanding the coupling between the urban sources of pollutants and their monitored status in the environment. This need stems from the fact that while policies and regulations aim at altering the strength of the diffuse sources, this strength can never be directly measured by 
field observations. A change in the strength of the diffuse source may, however, propagate to the environmental level of the pollutant, and thereby be indirectly detected. In order to understand the monitored levels of pollutants in response to their historical sources and to predict the effect of alteration of today's sources on future environmental levels of the heavy metals, it is important to be able to couple the monitored levels to the actual source terms.

In this study, we attempt assessing the coupling between sediment copper content, often analysed in environmental monitoring programs, and the urban sources of $\mathrm{Cu}$ in a complex, urban, aquatic system. Stockholm, Sweden, is such an example where diffuse sources are distributed over many urban activities and emitting into many, coupled basins from the upstream Lake Mälaren to the downstream archipelago of the Baltic Sea.

Source analyses of $\mathrm{Cu}$ for isolated recipients or entire municipalities have been frequently published in the literature [1-4]. Fate models for $\mathrm{Cu}$ in lakes have been suggested by e.g., Lindström and Håkanson [5], Woodfine et al. [6], Mackay et al. [7] and Heijungs [8]. Cui et al. [9] coupled a source analysis with a fate model for the small Lake Trekanten in Stockholm. In this work, we advance this coupling by suggesting an approach to assess a complex water system, where a multitude of diffuse, urban sources emit into many, coupled water bodies. The objectives of this communication are to:

- Present a conceptual model for the $\mathrm{Cu}$ flow from urban sources through a complex series of natural recipients;

- Test and demonstrate the conceptual model using Stockholm, Sweden, as a case study;

- Use literature data to deduce the trend in sediment $\mathrm{Cu}$ content along a flow path from Lake Mälaren, through Stockholm towards, the Baltic Sea.

\section{Urban sources of copper and delivery to the environment}

Today, major point sources of $\mathrm{Cu}$ have been managed in many urban environments in the industrialised world, and diffuse sources have become dominant [1]. As shown in Figure 1, important diffuse sources of $\mathrm{Cu}$ include traffic and building materials (see e.g., Sörme and Lagerkvist [2]). Copper is released to air or water, depending on the nature of release, e.g. as particles (traffic) or by leaching by precipitation (building materials). Airborne $\mathrm{Cu}$ may be scavenged to soil or surface water or is exported out of the recipient's catchment.

The fractions of waterborne $\mathrm{Cu}$ that go to storm water, surface water or groundwater is determined by the landuse, e.g. traffic, residential, business, or recreational area (see summary in Cui et al. [9]). Depending on the storm water collection system, a part of the storm water may go directly to the recipient, while another part may be treated in a storm water treatment plant (SWTP). Generally, a major part of the $\mathrm{Cu}$ that has been deposited in the soil is retained there, but a minor fraction may be transported to the recipient either directly with the groundwater (groundwater discharge) or by prior release to the surface water system (Figure 1). 
The diffuse urban sources of $\mathrm{Cu}$ brought to the recipient with the storm water can be estimated in at least two conceptually different ways. The first way to estimate the source term strength, $F$ [kg/year], is based on the volume of leachate $\mathrm{V}\left[\mathrm{m}^{3}\right.$ year $\left.^{-1}\right]$ and standard concentrations, $\mathrm{C}_{\mathrm{std}, \mathrm{n}}\left[\mathrm{kg} \mathrm{m}^{-3}\right]$, of $\mathrm{Cu}$ for storm water from different landuses $(n)$ :

$$
F=\sum_{n} V_{n} C_{s t d, n}
$$

where $\mathrm{V}_{\mathrm{n}}$ can be measured or estimated from precipitation, $P$ [m year ${ }^{-1}$, runoff coefficients, $Y[-]$, and the fraction, $\beta[-]$ of storm water that goes directly to the recipient, without passing a SWTP. This type of quantification was used by the municipality of Stockholm for some of the lakes in the case study in Section 5 [10] and is detailed in connection to the Stormtac model [11].

The second way of quantify the source term is based on the actual activities $(m)$ in the catchment of the recipient:

$$
F=\sum_{m} \sum_{n} \alpha_{m} \beta_{n} E_{m n}
$$

In Eqn. (2), $\alpha$ [-] is the fraction of released $\mathrm{Cu}$ that goes to storm water. $E$ [kg/year] is the emission by the activity, e.g. road traffic of presence of $\mathrm{Cu}$ roof, with a quantification that is based on activity specific wear or leaching rates of the goods [2,9]. Cui et al. [12] compares the two approaches. Groundwater and surface water contributions and atmospheric deposition of $\mathrm{Cu}$ can be handled in analogy to Eqn. (1) or (2) (see, for example, Cui et al. [9, 12]).

Urban point sources of $\mathrm{Cu}$ may include SWTP and industrial and municipal waste water treatment plants, landfills, and industrial and potentially environmental hazardous activities within the catchment. Point source can be quantified similarly to Eqn. (1), based on specific source information.

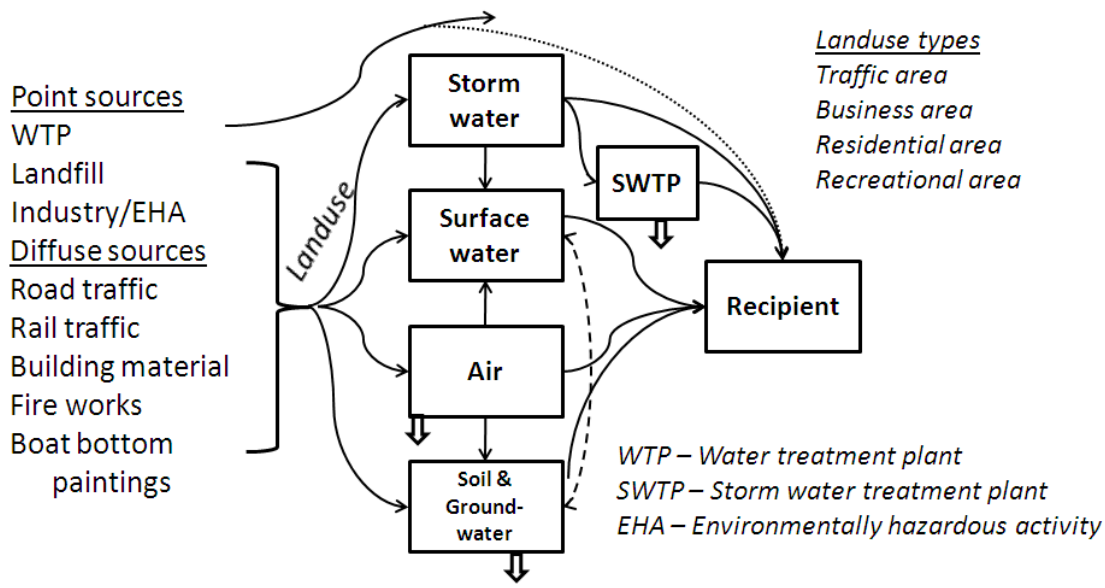

Figure 1: Pathways for $\mathrm{Cu}$ from the sources to the recipient in the urban environment. 


\section{Fate of copper in the recipient}

Copper from urban activities enters the recipient in particle form and dissolved in the aqueous phase through the pathways shown in Figure 1. Within the recipient, the limnology governs the fate of the $\mathrm{Cu}$ (Figure 2), where chemical conditions determine the partitioning between the dissolved and the particle form. Copper may leave the recipient in both forms. Particle-bound $\mathrm{Cu}$ is also subject to deposition in the sediments. Particles deposited into erosion or transport bottoms (ET-bottoms) are readily resuspended again. Particles deposited into accumulation bottoms (A-bottoms) rest there. The sediment in the accumulation bottoms is with time buried, and is then prevent from direct interaction with the water pillar. In both A- and ET-areas, dissolved $\mathrm{Cu}$ may be transported between the sediments and the water pillar through diffusion and advection.

The transfer of $\mathrm{Cu}$ between the different compartments in Figure 2 can be quantified by first-order approximations, as suggested by Lindström and Håkanson [5] and discussed by Cui et al. [9, 12]:

$$
F_{j}=R_{j} M_{i}
$$

where $F_{j}\left[\mathrm{~kg}\right.$ year $\left.{ }^{-1}\right]$ is the $\mathrm{Cu}$ flux of process $j, M_{\mathrm{i}}[\mathrm{kg}]$ is the mass of $\mathrm{Cu}$ in compartment $i$, and $R_{j}$ [year ${ }^{-1}$ ] is the transfer rate constant of process $j$. In the literature, the quantification of the transfer rate constant has been empirical, but process based (see e.g., Håkanson [13]).

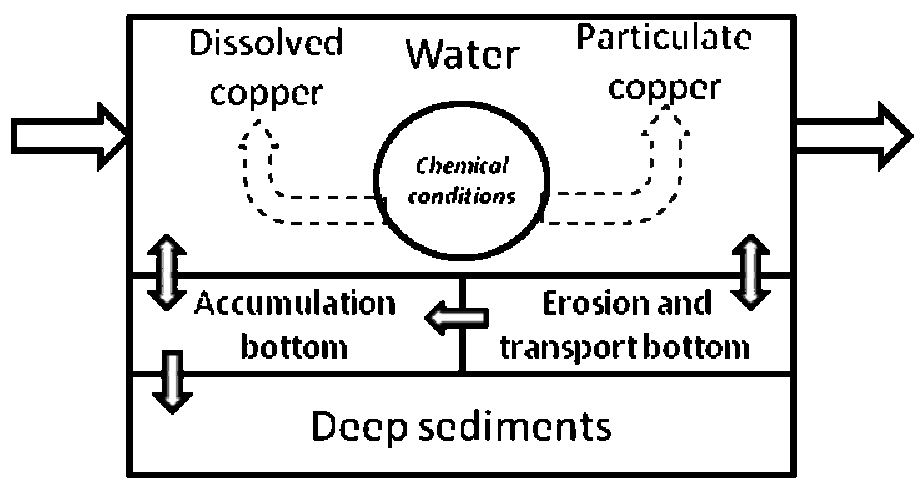

Figure 2: $\quad$ Fate of $\mathrm{Cu}$ in the recipient (modified from Lindström and Håkanson [5] and Cui et al. [9]). The arrows represent transfer of $\mathrm{Cu}$ between the different compartments for $\mathrm{Cu}$ in the aquatic environment (water pillar, surfacial sediment in accumulation, erosion and transport bottoms and the deep sediment).

The conceptual model in Figure 2 assumes the water pillar to be fully mixed. However, water bodies with little flow and/or considerable depth may become stratified, preventing mixing of surfacial water with bottom water. For these types of systems, a compartmentalisation of the water pillar into upper and lower 
water masses, with only partial and episodic mixing, may be relevant. The mixing fluxes can be handled similarly to other transfers, Eqn. (3), after handling of the timing of mixing. (see e.g., Håkanson and Bryhn [14]).

\section{Conceptual model for copper sources and fate in a complex system of urban recipients}

In this work, we are interested in following $\mathrm{Cu}$ from its urban source through the surface water system, in order to see if the anthropogenic contribution can be traced along the flow path. In the following, we suggest a conceptual model for this assessment. For clarity, we address the general case in Figure 3, where the flow path of interest is marked by a dotted line, and $\mathrm{Cu}$ is released from a multitude of activities in the urban area and emitted into several recipients. Challenges in formulating a quantifiable conceptual model for such a system include particularly the establishment of system boarders, the description of the fate of the pollutants in the coupled recipients, and the definition of the urban catchment for the source quantification. These issues are discussed here and the implementation of the approach in a case study is explained in Section 5.

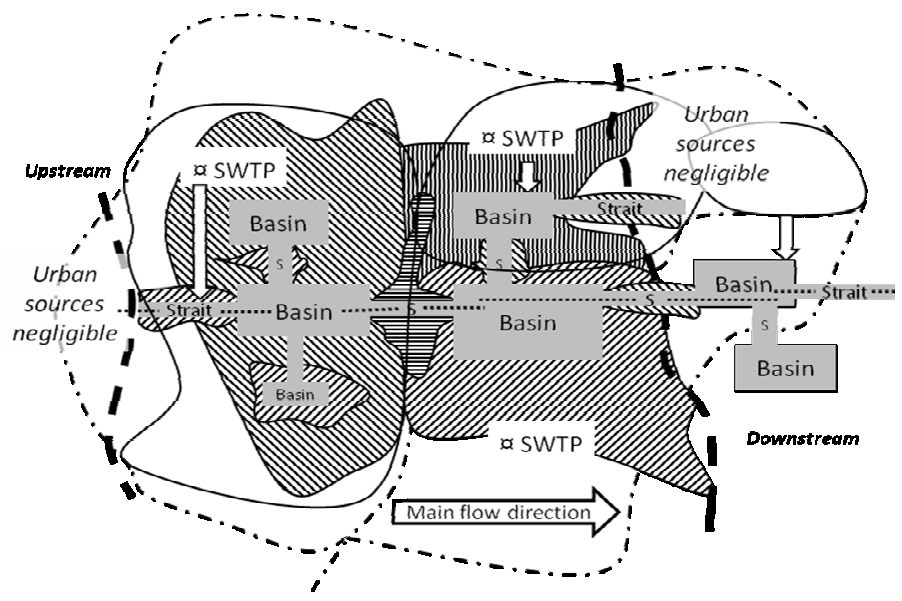

Figure 3: General geographic structure of the urban pollutant catchment system along a considered flow path (dotted line). Basins and straits (grey) and their surface water catchments (hatched areas); storm water catchments (full line), storm water treatment plants (SWTP) and municipality boarders (dash-dot line). Thick, broken lines show upstream and downstream boarder for urban $\mathrm{Cu}$ sources.

\subsection{System boarders}

We suggest that the upstream system boarder can be set where the urban source is insignificant (broken line in Figure 3). This boarder may be estimated from 
source term considerations (see Sections 2 and 4.3) or through monitored environmental levels of the pollutant. The downstream system boarder is set by the extension of the considered flow path out of the urban area. As discussed in the case study below, it may be convenient to extend the considered area to municipality/surface or storm water catchment boarders. Note that all surface waters with an urban source of $\mathrm{Cu}$ that are connected to the considered path must be included in the assessment.

\subsection{Propagation and fate of copper downstream of the source}

To consider the transport of $\mathrm{Cu}$ through the system of recipients, we propose to follow the approach of Engqvist and Andrejev [15] and divide the surface water into connected basins and straits based on geometric form, with straits being narrow, with an associated, expected lower water residence time (Figure 3). In order to trace the $\mathrm{Cu}$ through the system, the water flow through the straits between the basins must be established. Here, it must be noted that if the flow is bidirectional, partial mixing of water between basins must be considered, which complicates the mathematical coupling of the basins.

As a first approximation, we suggest considering straits as non-reactive channels for the $\mathrm{Cu}$, such that sediment deposition and internal loading of $\mathrm{Cu}$ is insignificant; urban sources of $\mathrm{Cu}$ may, however, contribute $\mathrm{Cu}$ to the straits (compare Figure 3). We propose to use the methods described in Section 3 to quantify the fate of $\mathrm{Cu}$ in each basin. We suggest that basins and straits are quantitatively coupled in the model through mass-balance considerations, such that the $\mathrm{Cu}$ outflow of an upstream basin arrives in a downstream basin.

\subsection{The urban catchment of copper}

In quantifying the sources of $\mathrm{Cu}$, we suggest that each basin and strait must be considered separately, as $\mathrm{Cu}$ may be significantly retarded in upstream basins. In the source quantification, a crucial part is to delineate the urban catchment of each basin and strait. Here, the catchment of ground- and surface water carrying $\mathrm{Cu}$ must be considered (compare Section 2 and Figure 3). However, a dominant contribution of $\mathrm{Cu}$ generally comes with storm water and cleaned waste water, which also must be considered. Each urban area has its own water management plan, which may cut over municipality boarders, that needs to be considered. As explained in Section 2, storm water may go directly to the recipient, be treated in a SWTP, or go to the soil, with the distribution being case-specific, and not necessarily well known.

This also implies that a storm water source may be geographically separated from its recipient, with water being lead to the recipient after potential treatment in a (distant) SWTP. Further redirection of precipitation within the urban area may occur as an effect of snow removal, in which case placement of snow deposits must be considered. It is noteworthy that the $\mathrm{Cu}$ sources that affect the considered flow path may be situated in several municipalities, possibly with separate storm water treatment facilities and environmental monitoring plans, thus providing separate "data catchments". 


\section{The Stockholm case study}

Stockholm is the capital of Sweden and is situated between the fresh water Lake Mälaren in the west and the archipelago of the lightly saline Baltic Sea in the east. The city is built on the islands and the coast line of the two water bodies, with $30 \%$ of the inner city area being water. In this study, we assess the flow path depicted as a dotted line in Figure 4 that also represents the main water flow direction from Lake Mälaren towards the Baltic Sea, transecting the municipalities of Stockholm, Lidingö, Nacka, Vaxholm, and Värmdö.

In 2007, the county of Stockholm had 1950000 inhabitants, with $\sim 65 \%$ within the urban area. Historically, the water bodies surrounding Stockholm received extensive amounts of urban pollutants through unmanaged point sources and waste water [16]. Today, point sources of $\mathrm{Cu}$ have been largely managed and diffuse sources dominate [1]. Important diffuse sources include copper roofs, traffic (through brake linings, asphalt wear, and tires) and atmospheric deposition of $\mathrm{Cu}$ originating in more distant areas. Part of the $\mathrm{Cu}$ emitted from the diffuse sources goes directly to the recipient, while a major part is stored in the soil $[17,18]$, and yet a dominant part goes to the storm water treatment facilities (compare Section 2).

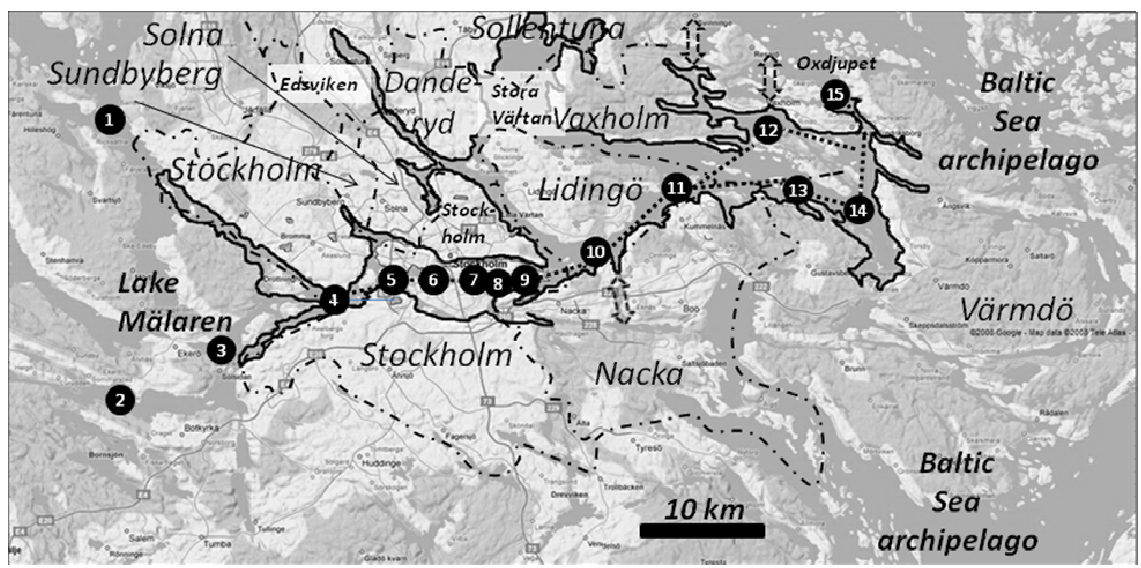

Figure 4: The urban area of Stockholm (white area) is situated between Lake Mälaren in the west and the Baltic Sea archipelago in the east. The dotted line marks our considered flow path and numbered spots refer to locations of reported sediment $\mathrm{Cu}$ contents (Figure 5). The full line is the water system boarder of our model. The broken line shows municipality boarders.

Jonsson and Sörme [19] suggest that within the municipality of Stockholm, ca 1 tonne of $\mathrm{Cu}$ per year goes directly from the diffuse sources, dominated by traffic, and another 0.25 tonne year ${ }^{-1}$ through the storm water treatment plants, after $90 \%$ removal, to the recipients. The sewage/storm water treatment plants 
(generally combined) contribute another 0.65 tonne year ${ }^{-1}$ of $\mathrm{Cu}$ to the recipients [19], as a point source, mainly from the tap water system (brass/copper pipes and taps) and food faeces, with a small contribution from car washes [2]. Discharging groundwater provide a minor contribution of $\sim 30 \mathrm{~kg}_{\text {year }}{ }^{-1}$ to the recipients within the municipality of Stockholm, according to Aastrup and Thunholm [20].

Burman [21] reports that ca. 0.25 tonne of $\mathrm{Cu}$ was distributed by the fireworks within Stockholm during the 2000 New Year's celebration, a fraction of which arrived to the nearby recipients. This indicates that fireworks may be a substantial, but non-dominant $\mathrm{Cu}$ contributor in the considered system. Antifouling bottom paints on boats are possibly also a source of $\mathrm{Cu}$. Elevated sediment $\mathrm{Cu}$ contents have been detected in one of the marinas just outside the considered system [22], but there are not yet any estimates of the annual emissions of $\mathrm{Cu}$ from these sources within Stockholm in the literature.

Diffuse and point sources of $\mathrm{Cu}$ within the municipality of Stockholm are generally well known and documented as shown above. Emissions of $\mathrm{Cu}$ within the other municipalities affecting the considered flow path (Figure 4) have to a lesser degree been reported in the literature, but must also be considered.

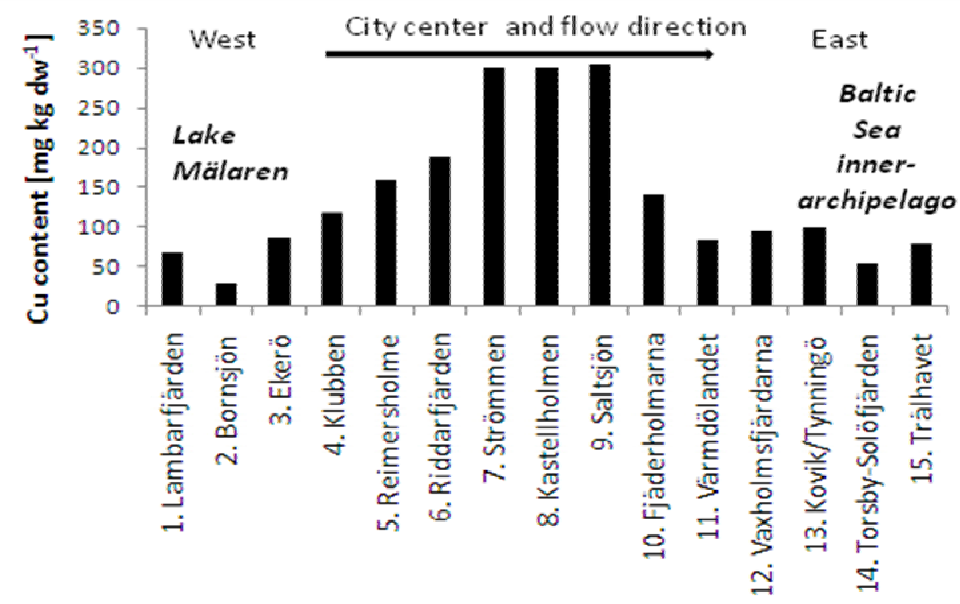

Figure 5: Average of the sediment $\mathrm{Cu}$ content in the upper $2 \mathrm{~cm}$ during 1997-2006 along the flow path in Figure 4 as reported by Lindström et al. [23], Rauch [24], and Sternbeck et al. [25]. The arrow shows the extent of the city centre and the main water flow direction.

\subsection{Trends in sediment copper contents along a flow path}

Figure 5 shows the average of the $\mathrm{Cu}$ content in the upper sediments along the flow path in Figure 4 as reported for 1997-2006 [23-25]. It is noteworthy that in Lake Mälaren, west and upstream of Stockholm, the $\mathrm{Cu}$ content is relatively low, 
increasing along the flow path as it passes through Stockholm. The $\mathrm{Cu}$ content in the sediment is lower east of the city centre, approaching and passing through the inner archipelago. This confirms a considerable urban effect on the $\mathrm{Cu}$ content of the sediments.

\subsection{Copper source and fate conceptual models for Stockholm}

Following the conceptual model in Section 4, the water system boarder was defined by the expected area of urban $\mathrm{Cu}$ contribution and the major water exchange path (see Figure 4, full line). According to Figure 5, this system includes the area with evidently elevated sediment $\mathrm{Cu}$ content. While several distant upstream cities and municipalities may contribute $\mathrm{Cu}$ to the considered system, this contribution is expected to be low, as surface water concentration of $\mathrm{Cu}$ generally is low. For convenience, we have thus used the Stockholm municipality boarder as our western system boarder. We include the bays of Edsviken and Stora Värtan north of the considered flow path, as it was estimated that non-negligible sources of $\mathrm{Cu}$ can be expected from the roads and traffic in the nearby areas [26]. A few lakes in this area were excluded from the system, but may need to be considered as recipients of part of this $\mathrm{Cu}$ (not shown).

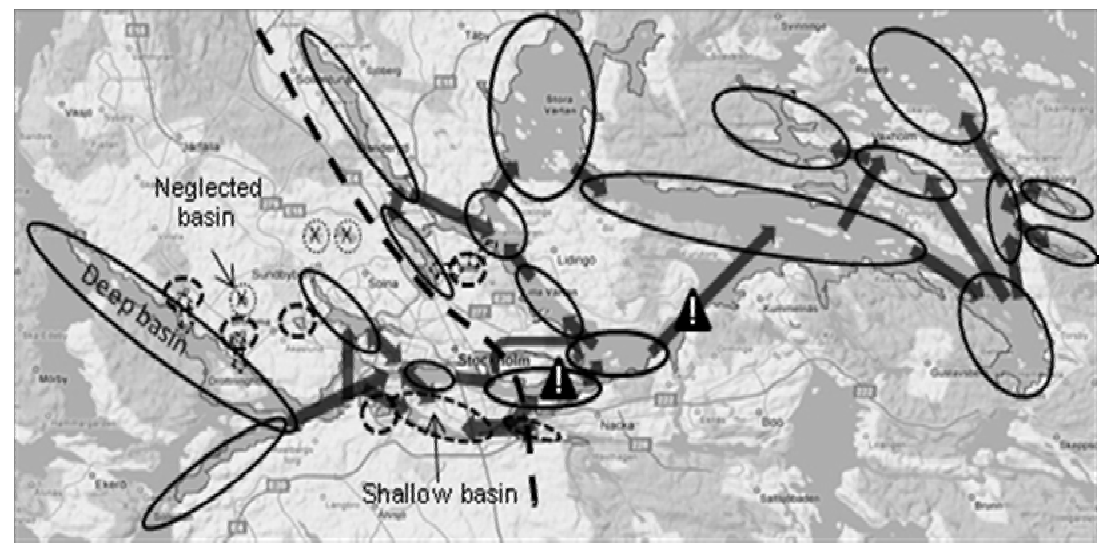

Figure 6: The subdivision of the considered water system (Figure 4) into basins (ellipses; deep - full contour; shallow - dashed contour) and straits (arrows; surface water - filled; underground/ groundwater - dotted). Neglected basins within the more urban area have been crossed out. Broken line divides the inner archipelago from Lake Mälaren/transition zone. Triangle with exclamation mark shows the approximate position of WTP water outlet.

As the eastern boarder of the system, we propose to use Oxdjupet, close to Point 15 in Figure 4, as this represents the major water exchange point between the inner- and the outer archipelago, neglecting two smaller exchange points to 
the west (marked by dashed arrows in Figure 4). The water exchange point to the south at Skuru has also been excluded, as only little water is exchanged between the considered system and the southern archipelago, not assessed here. Tentatively, we ignore contributions of $\mathrm{Cu}$ from the Baltic sea.

For the archipelago, Engqvist and Andrejev [15] already suggested a partitioning into basins and straits; for Lake Mälaren and the transitional region, we consider the water bodies with slender form as straits, whereas others were considered as basins (Figure 6). Basins with a maximum depth of more than $10 \mathrm{~m}$ were considered deep (full contour ellipse in Figure 6), whereas the rest were considered shallow (dashed contour ellipse in Figure 6). We suggest that the shallow basins can be modelled as fully mixed, whereas thermal stratification in the deep basins requires their compartmentalisation into a deeper and a shallower part in the lake fate model (see Section 3). A few small basins with no or little connection to other parts of the water system under consideration were neglected for simplicity (crossed-out basins in Figure 6). Furthermore, many lakes in some more rural areas, south and east of the city centre, were not considered as they will neither contribute nor prevent $\mathrm{Cu}$ from reaching the flow path, as a first approximation (not shown in Figure 6).

\section{Discussion}

\subsection{The conceptual model and its quantification}

In this work, we have proposed a way to assess the urban copper sources and the fate of copper as it is transported through a complex aquatic system (Section 4). The approach is based on a source quantification, through a substance flow analyses (Section 2), that is coupled with a dynamic fate modelling (Section 3). Application of the model to the case of Stockholm (Section 5) highlighted a number of scientific challenges that will be discussed here.

\subsubsection{System boarders}

While the definition of the geographical system boarders may be unproblematic, the handling of small lakes within the system may pose considerable difficulty. Including lakes that are unimportant for the considered flow path adds unnecessary complexity to the model, and demands a greater amount of field data. We propose that small lakes with no or insignificant surface water exchange with the considered flow path need only to be considered as sinks for the urban $\mathrm{Cu}$ in the source analysis, and can be excluded from the fate model. However, this needs to be further investigated. In Section 5.2, we discuss that urban waters judged to contribute little $\mathrm{Cu}$ may be considered to be left out of the system; in our case, Edsviken and Stora Värtan and their catchments were tentatively kept within the system.

\subsubsection{Propagation and fate of copper downstream of the source}

Mapping the water system into basins and straits is obviously a source of uncertainty in the proposed model, as is the partitioning into shallow and deep 
basins. In our case study, we have implicitly suggested a rather rough handling, with for example small bays being lumped with bigger basins or straits. The choice of spatial discretisation can be investigated using a sensitivity analyses in a quantitative model. Availability of input data for the source and fate models as well as of monitoring data to test the model will ultimately limit the level of geographical details that is meaningful to describe.

We have identified water exchange between basins and particularly bidirectional flow between and episodic mixing of basins as major conceptual difficulties to overcome, and also associated with data gaps in our considered case study. As a first approximation, we suggested the straits to be handled as non-reactive channels for $\mathrm{Cu}$, in order to ease the source quantification. The implications of this simplification must be tested.

\subsubsection{The urban catchment of copper}

A major difficulty in the source quantification is the establishment of the urban catchment, as detailed in Section 4.3. The actual source quantification within the catchments is associated with further uncertainty. This uncertainty is related to data availability with respect to traffic work, amount of $\mathrm{Cu}$ bearing goods and its leaching rates, the collection and treatment of storm water, etc. Also in wellinvestigated municipalities, like the municipality of Stockholm, not all data are at hand. The effect of such uncertainties on predicted levels of $\mathrm{Cu}$, as the uncertainties propagate through the model, can be assessed by sensitivity analyses.

\subsection{Towards a quantitative model for Stockholm - data availability}

In a case study, we propose a coupling of source and fate sub models for $\mathrm{Cu}$ along a main water flow path through Stockholm. Dominant information needed in the source quantification includes landuse area, storm water collection, and traffic work, as well as extent of copper roofing (see summary by Cui et al. [9]). For the central municipality of Stockholm, the $\mathrm{Cu}$ emissions have been well researched and documented, as summarised above for the municipality as a whole.

For the individual basins/straits the information is in many cases also available in the literature [27] or through the authorities (e.g., Stockholm EPA). A detailed assessment of the small Lake Trekanten, just south of the considered flow path in Figure 4, was reported by Cui et al. [9] and a few additional lakes north of the flow path is being reported by Cui et al. [12]. For the municipalities surrounding Stockholm, less information is readily available. Monitoring data of particularly sediment $\mathrm{Cu}$ content over time in several basins/straits along with data for source quantification will be essential for model testing.

Particularly important data needs for the fate model include water exchange between basins. Through the work of Engqvist and Andrejev [15], this is generally available for the inner archipelago (Figure 6). However, for the parts of Lake Mälaren and the transition zone to the archipelago, less information is readily available. Here, it must be emphasized that it is not sufficient with the net water exchange between basins, as episodic change of flow direction implies a 
partial mixing of waters with potentially different $\mathrm{Cu}$ levels. We suggest that model sensitivity tests may help deducing the level of details needed in this water flow description, in order to match other uncertainties in the fate model.

\section{Conclusions}

Using literature data, we showed that there is a peak in the $\mathrm{Cu}$ content of the upper, aquatic sediments sampled during 1997-2006 close to the city centre of Stockholm (Figure 5). Upstream (west) of Stockholm, in Lake Mälaren, and downstream, in the inner Baltic Sea archipelago, the $\mathrm{Cu}$ content is lower, confirming the urban origin of this $\mathrm{Cu}$ (see also Lindström et al. [23], Rauch [24], and Sternbeck et al. [25]). We proposed that such elevated levels of $\mathrm{Cu}$ in the aquatic sediment can be quantitatively coupled to the urban $\mathrm{Cu}$ sources.

We also proposed an approach to quantitatively follow $\mathrm{Cu}$ from its urban source through a complex, aquatic system. The approach combines a substance flow analysis [2] for the urban sources of $\mathrm{Cu}$ with a mass-balance model for its environmental fate [5] through a series of natural recipients (Section 4). As detailed site data generally is an obstacle to site or case modelling, the approach is simple, rather than sophisticated.

We applied the proposed model to a main water path from Lake Mälaren to the Baltic Sea archipelago, through Stockholm, in Sweden (Figure 4). This represents a case where a multitude of point and diffuse sources, distributed over many urban activities, emit into many, coupled water bodies. In the case study, we proposed definition of the system boarders and partitioning of water bodies into straits and deep and shallow basins, based on geometric form (Figure 6). We suggested that compliance of future quantitative model results with monitoring data may help testing the choices made in this conceptual model. We proposed that data needed for such model testing includes particularly sediment $\mathrm{Cu}$ contents at a few separate times for several of the basins/straits along with source quantifications during a similar time period.

Here, we propose that the quantitative coupling of the urban sources and the monitored levels of pollutants, as aimed for in this study, is crucial for understanding monitoring results in the light of historical sources, which may help formulating policies and assessing different management scenarios. Furthermore, model results and sensitivity analyses may help establishing the monitoring needs, in order to follow the response of environmental $\mathrm{Cu}$ levels to different pollution management actions and city developments within a complex aquatic system.

\section{References}

[1] Sörme, L., Bergbäck, B. \& Lohm, U., Century perspective of heavy metal us in urban areas. A case study in Stockholm. Water, Air, \& Soil Pollution: Focus, 1(3), pp. 197-211, 2001. 
[2] Sörme, L. \& Lagerkvist, R., Sources of heavy metals in urban wastewater in Stockholm. Science of the Total Environment. 298(1-3), pp. 131-145, 2002.

[3] Spatari, S., Bertram, M., Gordon, R. B., Henderson, K. \& Graedel, T. E., Twentieth century copper stocks and flows in North America: A dynamic analysis. Ecological Economics. 54(1), pp. 37-51, 2005.

[4] Rule, K. L., Comber, S. D. W., Ross, D., Thornton, A., Makropoulos, C. K. \& Rautiu, R., Diffuse sources of heavy metals entering an urban wastewater catchment. Chemosphere. 63(1), pp. 64-72, 2006.

[5] Lindström, M. \& Håkanson, L., A model to calculate heavy metal load to lakes dominated by urban runoff and diffuse inflow. Ecological Modelling. 137(1), pp. 1-21, 2001.

[6] Woodfine, D. G., Seth, R., Mackay, D. \& Havas, M., Simulating the response of metal contaminated lakes to reductions in atmospheric loading using a modified QWASI model. Chemosphere. 41(9), pp. 1377-1388, 2000.

[7] Mackay, D., Di Guardo, A., Paterson, S. \& Cowan, C. E., Evaluating the environmental fate of a variety of types of chemicals using the EQC model. Environmental Toxicology and Chemistry. 15(9), pp. 1627-1637, 1996.

[8] Heijungs, R., Dynabox: a dynamic multi-media fate model for the case of heavy metals (Part II.5), Heavy metals: a problem solved, ed. E. van der Voet, Kluwer Academic Publishers: Dordrecht, pp. 65-76, 2000.

[9] Cui, Q., Brandt, N. \& Malmström, M. E., Sediment metal contents as indicators of urban metal flows in Stockholm, ConAccount 2008 "Urban metabolism: measuring the ecological city". (In print), 2009.

[10] Lännergren, C. Personal communication, Feb 2009, Stockholm Vatten AB, Stockholm, Sweden.

[11] Larm, T., Watershed-based design of stormwater treatment facilities: Model development and applications, Royal Inst Tech., Stockholm, 2000.

[12] Cui, Q., Brandt, N. \& Malmström, M.E., Manuscript in preparation, 2009.

[13] Håkanson, L., Metals in lakes: field and modeling results on remedial strategies with a focus on mercury and radiocesium, Geochemical approaches to environmental engineering of metals, ed. R. Reuther, Springer, pp. 107-152, 1996.

[14] Håkanson, L. \& Bryhn, A.C., A Dynamic mass-balance model for phosphorus in lakes with a focus on criteria for applicability and boundary conditions. Water, Air, \& Soil Pollution. 187(1), pp. 119-147, 2008.

[15] Engqvist, A. \& Andrejev, O., Water exchange of the Stockholm archipelago - cascade framework modelling approach. Journal of Sea Research. 49(4), pp. 275-294, 2003.

[16] Johansson, L. \& Wallström, K., Urban impact in the history of water quality in the Stockholm archipelago. AMBIO. 30(4), pp. 277-281, 2001.

[17] Bergbäck, B., Johansson, K. \& Mohlander, U., Urban metal flows - A case study of Stockholm. Review and conclusions. Water, Air, \& Soil Pollution: Focus. 1(3), pp. 3-24, 2001. 
[18] Linde, M., Bengtsson, H. \& Öborn, I., Concentrations and pools of heavy metals in urban soils in Stockholm, Sweden. Water, Air, \& Soil Pollution: Focus. 1(3), pp. 83-101, 2001.

[19] Jonsson, A. \& Sörme, L.,Sources of Copper and Zinc to the aquatic recipients of Stockholm, Sweden, The trace of metals - use, emissions and sediment load of urban heavy metals (Paper V), PhD Thesis, University of Linköping, Sweden, 2000.

[20] Aastrup, M. \& Thunholm, B., Heavy Metals in Stockholm groundwaterconcentrations and fluxes. Water, Air, \& Soil Pollution: Focus. 1(3), pp. 25- 41, 2001.

[21] Burman, L. Förhöjda halter metaller i luften: Mätning i Stockholm under millenieskiftet, Rapporter från SLB-analys Nr. 3:00, Stockholm Luft- och Bulleranalys, Stockholm, Sweden.

[22] KEMIKALIEINSPEKTIONEN, Kemiska ämnen i båtbottenfärger - en undersökning av koppar, zink och Irgarol 1051 runt Bullandö marina 2004, Kemikalieinspektionen Rapport 2/06, Sundbyberg, Sweden, 2006.

[23] Lindström, M., Jonsson, A., Brolin, A. \& Håkanson, L., Heavy metal sediment load from the city of Stockholm. Water, Air, \& Soil Pollution: Focus. 1(3), pp. 103-118, 2001.

[24] Rauch, S., Trace elements in Stockholm sediments, Stockholms Stads Miljöförvaltning, Stockholm, Sweden, 2007.

[25] Sternbeck, J., Brorström-Lundén, E., Remberger, M., Kaj, L., Palm, A., Junedahl, E. \& Cato, I., WFD Priority substances in sediments from Stockholm and the Svealand coastal region, IVL Report 1538, IVL Swedish Environmental Research Institute, Stockholm, Sweden, 2003.

[26] Rolli, V., Heavy metal behaviour in urban complex aquatic system: Modelling study of copper sources and fate in Stockholm, Sweden, Master Thesis, POLITECNICO DI TORINO, Torino, Italy, 2009.

[27] Faktaunderlag-Vattenprogram för Stockholm 2000, STOCKHOLMS STAD, http://miljobarometern.stockholm.se 